\title{
Do Obese Patients after Weight Loss Become Metabolically Normal?
}

\author{
Vincent Makoundou ${ }^{\mathrm{a}} \quad$ Zoltan Pataky ${ }^{\mathrm{a}} \quad$ Elisabetha Bobbioni-Harsch ${ }^{\mathrm{a}}$ \\ Jean Pierre Gachoud ${ }^{b}$ Alain Golay ${ }^{a}$ \\ a Service of Therapeutic Education for Chronic Diseases, Department of Community Medicine and Primary Care, \\ Geneva University Hospital, boche Pharma (Schweiz) AG, Basel, Switzerland
}

\section{Keywords}

Obesity · Cardio-metabolic factors - Weight loss .

Weight maintenance

\section{Summary}

Objective: To compare the metabolic cardiovascular risk factors of obese patients after weight loss and 4-year weight loss maintenance afterwards against a matched control group of subjects with a stable body weight and without history of weight loss. Method: 50 obese non-diabetic subjects in the study group who previously lost $10 \%$ or more of their weight and afterwards entered a 4-year weight loss maintenance programme were matched by age, BMI and sex and compared to 50 weight-stable subjects without history of weight loss. The comparison between both groups was done in term of anthropometrical, metabolic and biological characteristics, early atherosclerosis and insulin sensitivity. Results: Anthropometrical, metabolic and biological characteristics were similar between the weight loss group and the control matched group. However, insulin sensitivity was still significantly lower in the weight loss than in the matched control group ( $p=0.02$ ). Intima media thickness (IMT) also was similar in both groups. We found that lower atherosclerosis measured by IMT at the level of the carotid is associated with better insulin sensitivity $(p<0.05)$. After the 4-year weight loss maintenance programme, insulin sensitivity improved in the post-weight loss group from $7.9 \pm 3.2$ to $8.4 \pm 3.6 \mathrm{mg} / \mathrm{kg} / \mathrm{min}$. Conclusion: All cardiometabolic parameters of obese subjects, except for insulin sensitivity, normalised completely after weight loss. The latter was improved by a weight loss maintenance programme if successfully completed.

\section{Introduction}

Numerous observational studies [1, 2] demonstrated that obesity coexists with a variety of cardiovascular risk factors and is related to a greater cardiovascular risk. Several studies also confirmed that obesity is associated with insulin resistance [3]. The latter amplifies dyslipidemia including high levels of low-density lipoprotein cholesterol (LDL-C) and decreased levels of high-density lipoprotein cholesterol (HDL-C) [4]. On the other hand, there is still a controversy concerning the relationship between insulin resistance and atherosclerosis measured by intima media thickness [5].

Clinical research in weight loss management has demonstrated that weight loss results in improvement of obesityrelated cardio-metabolic factors such as plasma glucose, triglyceride, total cholesterol, LDL-C, HDL-C, and hypertension [6]. Weight reduction also is associated with improvement of insulin sensitivity [7]. The metabolic benefits occur independently of the way by which the weight loss has been obtained [6]. Noakes et al. [8] demonstrated that an energy-restricted, high-protein, low-fat diet provide nutritional and metabolic benefits that are equal to and sometimes greater than those observed with a high-carbohydrate diet. The goal of this study is to evaluate if after weight loss or weight loss maintenance all cardio-metabolic parameters become normal.

The metabolic cardiovascular risk factors of 50 obese patients after weight loss (mean weight loss of 17\%) and 4-year weight loss maintenance afterwards were compared to a matched control group of 50 subjects with a stable body weight and without history of weight loss.

\begin{tabular}{ll}
\hline KARGER & ( 2011 S. Karger GmbH, Freiburg \\
1662-4025/11/0043-0218 $\$ 38.00 / 0$ \\
$\begin{array}{l}\text { Fax +49 7614520714 } \\
\text { Information@Karger.de } \\
\text { www.karger.com }\end{array}$ & $\begin{array}{l}\text { Accessible online at: } \\
\text { www.karger.com/ofa }\end{array}$
\end{tabular}




\section{Subjects and Methods}

\section{Study Population}

The study proceeded comparison of two groups: a study group and a matched control group. There were 50 obese non-diabetic subjects in the study group (5 men and 45 women) who previously lost $10 \%$ or more of their weight using a method already described. The weight loss period lasted $2.5 \pm 0.5$ years with a mean stable period for at least 6 months. Afterwards, the weight loss period was prolonged by a 4-year weight loss maintenance programme as previously described by our team [9-11]. But only 45 among 50 study subjects entered this maintenance phase. 34 among of them were able to maintain their body weight $82.3 \pm 15.2 \mathrm{vs}$. $82.5 \pm 17.1 \mathrm{~kg}$ ).

The control group had stable weight with no history of weight loss and was matched for age, BMI, and sex.

The comparison between both groups was done in terms of anthropometrical, metabolic and biological characteristics, early atherosclerosis, and insulin sensitivity.

\section{Physical Examinations}

Body weight, BMI, percent body fat and fat-free mass were evaluated by the TANITA bioimpedance balance (TANITA International Division, Yiewsley, UK). Waist circumference was measured by placing a measuring tape in a horizontal plane at the level of the iliac crest without compressing the skin. To measure the hip circumference, a measuring tape was placed horizontally at the widest part of the buttocks. Waist and hip values permit to calculate waist/hip ratio. Blood pressure was recorded after 5 min sitting.

\section{Insulin Resistance Measurement}

Euglycaemic hyperinsulinaemic clamp was performed in fasting state in both groups. After 4-year weight loss maintenance programme it was repeated only in the study group.

Subjects were attended to the clinic at 08:00 a.m. after overnight fasting. Two intravenous cannulas through antecubital vein were established, one for the blood sampling and the other one for insulin pump with glucose load. Before insulin and glucose load, blood samples were taken and sent to the central laboratory of Geneva University Hospital to determine lipid profile (total cholesterol, LDL-C, HDL-C, triglycerides, free fatty acids) and fasting plasma glucose. The target plasma glucose concentration was maintained between 4.5 and $5.5 \mathrm{mmol} / \mathrm{l}$ during insulin infusion at a rate of $240 \mathrm{pmol} / \mathrm{min} / \mathrm{m}^{2}$. Bedside plasma glucose was measured at each 5 -min intervals and if necessary with intermediate check up to ensure it remains within $0.8 \mathrm{mmol} / \mathrm{l}( \pm 15 \%)$ of the target glucose concentration. The steady-state period (for calculation of insulin sensitivity) was between 80 to 120 min.

\section{Intima Media Thickness Measurement}

Intima media thickness measurement was performed using ultrasound scanner. Both the left and right carotid arteries were scanned. The images were analysed in an automated computerised analysing system.

Carotid artery intima media imaging follows a validated protocol. Longitudinal B-mode image is taken of the right and left common carotid arteries (CCA) and of internal carotid artery (ICA) from anterior, lateral and posterior angles. The image was recorded on videotape and evaluated by a single reader.

Diastolic frames of CCA, carotid bifurcation, and ICA were selected to provide images of the near and far wall intima-media complex. Frames were digitised and analysed by an image analysis system (MIP: Institute of Clinical Physiology, CNR, Pisa, Italy) [12]. Lines are drawn along the lumen intima and media adventitial interfaces, and the intima media thickness is computed as an average of several measurements.
Table 1. Anthropometrical characteristics in both groups

\begin{tabular}{lll}
\hline Parameters & $\begin{array}{l}\text { After weight loss } \\
(\mathrm{n}=50)\end{array}$ & $\begin{array}{l}\text { Matched controls } \\
(\mathrm{n}=50)\end{array}$ \\
\hline Age & $43.3 \pm 11.0$ & $43.5 \pm 9.9$ \\
$\mathrm{M} / \mathrm{F}$ & $5 / 45$ & $5 / 45$ \\
Weight, $\mathrm{kg}$ & $82.3 \pm 15.2$ & $82.3 \pm 15.0$ \\
BMI, kg/mg & $30.2 \pm 5.7$ & $29.8 \pm 5.4$ \\
Lean body mass, kg & $50.6 \pm 9.5$ & $50.8 \pm 7.7$ \\
FM, kg & $32.2 \pm 10.8$ & $31.5 \pm 11.0$ \\
Waist circumference, cm & $92.2 \pm 12.7$ & $92.5 \pm 14.6$ \\
Hip circumference, cm & $107.54 \pm 12.05$ & $106.8 \pm 13.3$ \\
Waist/hip ratio & $0.9 \pm 1.0$ & $0.9 \pm 0.1$ \\
\hline
\end{tabular}

\section{Statistics}

Statistical analyses were performed using stata version 10 .

All values were presented as the mean $\pm \mathrm{SD}$. The significance of the comparisons of baseline characteristics was determine by ANOVA. A p value of less than 0.05 was considered statistically significant.

\section{Results}

Anthropometrical characteristics in the two groups (study group after weight loss and the matched control group) are shown in table 1.

Metabolic and biological characteristics are presented in table 2 and are similar between the two groups. However, insulin sensitivity was still significantly different in the weight loss group compared to the matched control group $(p=0.02)$.

Intima media thickness measured at the level of CCA and ICA and blood pressure comparison were also similar.

Impact of insulin sensitivity on intima media thickness was evaluated by comparison of CCA and ICA by quartiles of insulin sensitivity values as shown in table 3 . The results confirmed in both groups that lower atherosclerosis measured by intima media thickness at the level of the carotid is associated with better insulin sensitivity $(\mathrm{p}<0.05)$.

After 4-year weight loss maintenance programme, insulin sensitivity improved slightly in the weight loss group from 7.9 \pm 3.2 to $8.4 \pm 3.6 \mathrm{mg} / \mathrm{kg} / \mathrm{min}(\mathrm{p}=0.21)$. Comparison of insulin sensitivity between patients after weight loss and patients after weight loss maintenance (fig. 1) showed a slight improvement of insulin sensitivity after 4 years maintenance programme. This improved value became definitely not significantly different compared to the matched control group.

\section{Discussion}

The weight loss group reached similar values of lean body mass, fat mass, waist and hip circumference as well as waist/ hip ratio compared to a matched control group who had a sta- 
Table 2. Metabolic and biological characteristics in both groups

\begin{tabular}{lll}
\hline Parameters & $\begin{array}{l}\text { After weight loss } \\
(\mathrm{n}=50)\end{array}$ & $\begin{array}{l}\text { Matched control } \\
(\mathrm{n}=50)\end{array}$ \\
\hline Total cholesterol, mmol/l & $5.2 \pm 1.0$ & $4.9 \pm 1.0$ \\
HDL-C, mmol/l & $1.3 \pm 0.3$ & $1.4 \pm 0.4$ \\
LDL-C, mmol/l & $3.4 \pm 0.9$ & $3.0 \pm 0.9$ \\
Triglycerides, $\mathrm{mmol} / \mathrm{l}$ & $1.1 \pm 1.3$ & $1.1 \pm 0.6$ \\
Free fatty acid, mmol/l & $0.6 \pm 0.2$ & $0.6 \pm 0.3$ \\
Fasting plasma glucose, $\mathrm{mmol} / \mathrm{l}$ & $5.1 \pm 0.8$ & $5.0 \pm 0.4$ \\
Insulin sensitivity $(=$ glucose uptake $), \mathrm{mg} / \mathrm{kg} / \mathrm{min}$ & $7.9 \pm 3.2$ & $9.5 \pm 3.9 *$ \\
Systolic blood pressure, $\mathrm{mm} \mathrm{Hg}$ & $121.1 \pm 14.0$ & $119.4 \pm 13.9$ \\
Diastolic blood pressure, $\mathrm{mm} \mathrm{Hg}$ & $77.5 \pm 7.4$ & $77.3 \pm 8.5$ \\
Intima media thickness, $\mathrm{mm}$ & & \\
$\quad$ Common coronary arteries & $0.6 \pm 0.1$ & $0.6 \pm 0.1$ \\
$\quad$ Internal carotid artery & $0.6 \pm 0.1$ & $0.7 \pm 0.1$ \\
\hline *p $=0.02$. & & \\
\hline
\end{tabular}

ble weight with no history of weight loss for 1 year. Lipid profiles and fasting glucose were also similar. These facts underline and confirm previous findings of authors such as Anderson et al. [13] who demonstrated that weight loss is associated with improvement in biological parameters and clinical signs. Even moderate weight reduction of at least $5 \%$ of the initial body weight is known to improve risk factors for obesity-associated complications: improvement in glucose metabolism, reduced blood pressure, and improvement in blood lipid levels [14].

The beneficial effect remains as long as the weight loss is maintained [15]. Dyslipidaemia also is usually improved in case of weight loss [16]; our weight loss group normalised completely their lipid values.

Win and Hill [17] also demonstrated that more favourable metabolic changes are obtained with weight loss of $10 \%$. Since then both definitions (regarding improvement induced by $5 \%$ or $10 \%$ of weight loss) have been adopted and used by other authors in several studies $[18,19]$. Our subjects had lost an average $17 \%$ of weight which is above the proposed threshold. Our data support those of the literature that after weight reduction all metabolic parameters reached that of the matched control group. However, insulin sensitivity was still significantly lower in the weight loss group compared to the matched control group.

Weight loss through caloric restriction is known to attenuate and even reverse insulin resitance [20]. Schenk et al. [21] found that enhanced insulin sensitivity after weight loss was primarily mediated by a reduction in fatty acid mobilisation. Interestingly, when weight loss is not accompanied by a reduction in fatty acid mobilisation, insulin sensitivity is not improved. A study by Klein et al. [22] reported that large-scale liposuction that resulted in the removal of a substantial amount of body fat (i.e. $10 \mathrm{~kg}$ of body fat) did not reduce fatty acid mobilisation and insulin sensitivity was not improved. Interestingly, we noticed that after weight loss fatty acid mobilisation was similar to that of the control group while insulin sensitivity was not. On the other hand, after 4

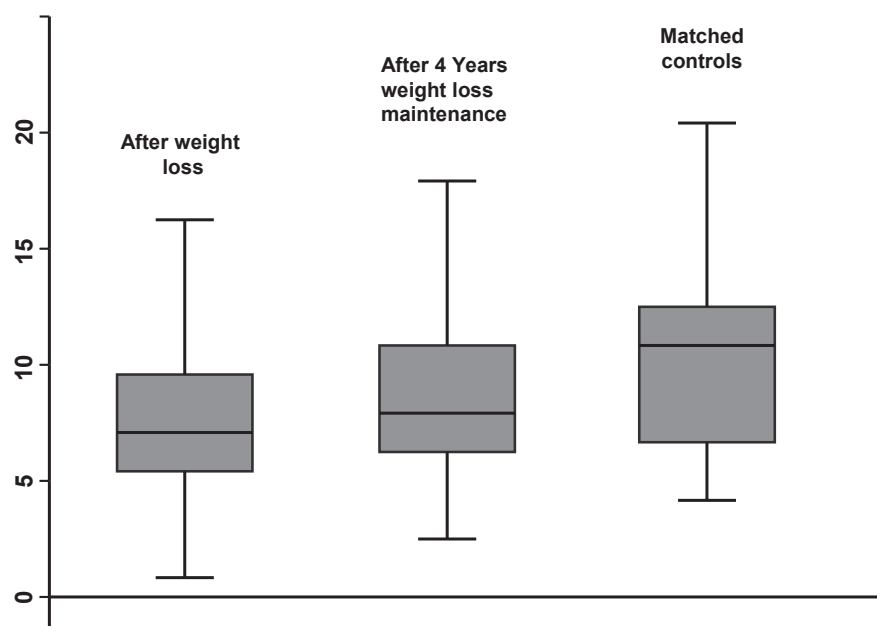

Fig. 1. Insulin sensitivity after weight loss, after weight loss maintenance compared to matched control.

years weight loss maintenance, insulin sensitivity improved reached values not significantly different from those of the control group.

Possibly as long as the fatty acid mobilisation will be kept at the lower value the insulin sensitivity may stay better. Oyama et al. [23] found that the magnitude of weight loss influenced insulin sensitivity more than the intervention time. Unfortunately, we could not find any data in the literature by which time a normalisation of insulin sensitivity could be achieved during the weight loss or weight loss maintenance process.

In both groups, intima media thickness was analysed according the insulin sensitivity quartiles. Intima media thickness of the 1st quartile of insulin sensitivity (insulin resistant) was significantly higher when compare to the $4 \mathrm{rth}$ quartile of insulin sensitivity (more sensitive).

The association between insulin resistance and carotid intima media thickness has been assessed in several populations, including Europeans, Chinese, Hispanics, and Black 
Table 3. Atherosclerosis and insulin sensitivity in both groups

\begin{tabular}{lll}
\hline Intima media thickness, mm & $\begin{array}{l}\text { Insulin resistant } \\
(1 \text { st quartile) }\end{array}$ & $\begin{array}{l}\text { Insulin sensitive } \\
\text { (4th quartile) }\end{array}$ \\
\hline $\begin{array}{l}\text { After weight loss } \\
\text { Common carotid arteries }\end{array}$ & $0.610 \pm 0.064$ & $0.564 \pm 0.079^{*}$ \\
$\begin{array}{l}\text { Internal carotid artery } \\
\text { Matched control group }\end{array}$ & $0.613 \pm 0.098$ & $0.612 \pm 0.115$ \\
Common carotid arteries & $0.611 \pm 0.071$ & $0.581 \pm 0.066^{*}$ \\
Internal carotid artery & $0.659 \pm 0.113$ & $0.612 \pm 0.107^{*}$ \\
\hline
\end{tabular}

$* \mathrm{p}<0.05$.

Americans, using several different indexes of insulin resistance including HOMA. Several studies [24, 25] have found insulin resistance to be positively associated with carotid intima media thickness.

These results are in accordance with previous finding by Hidvegi et al. [26, 27]. They demonstrated that early and asymptomatic signs of carotid atherosclerosis could be detected in subjects who showed insulin resistance.

\section{Conclusion}

All cardio-metabolic parameters of obese subjects, except for insulin sensitivity, normalised completely after weight loss.

After a 4-year weight loss maintenance programme, insulin sensitivity improved and became statistically not different from that of the matched control. Thus it seems that successful weight loss maintenance must last for a considerable time to achieve normalisation of insulin sensitivity.

The intima media thickness measured in both groups did not differ significantly. On the other hand, we found that more sensitive subjects in both groups displayed less intima media thickness.

\section{Acknowledgement}

This study was supported by a research grant from Roche Pharma (Schweiz) AG.

\section{Disclosure Statement}

There is not any conflict of interest for each author.

\section{References}

1 Wilson PW, D'Agostino RB, Sullivan L, Parise H, Kannel WB: Overweight and obesity as determinants of cardiovascular risk: the Framingham experience. Arch Intern Med 2002;162:1867-1872.

2 Janssen I, Katzmarzyk PT, Ross R: Body mass index, waist circumference, and health risk: evidence in support of current National Institutes of Health guidelines. Arch Intern Med 2002;162:207-209.

$\checkmark 3$ Bonora E, Kiechl S, Willeit J, Oberhollenzer F, Egger G, Meigs JB, Bonnadona RC, Muggeo M Insulin resistance as estimated by homeostasis model assessment predicts incident symptomatic cardiovascular disease in Caucasian subjects from the general population: the Bruneck study. Diabetes Care 2007;30:318-324.

4 Eckel RH, Grundy SM, Zimmet PZ: The metabolic syndrome. Lancet 2005;365:1415-1428.

$\checkmark 5$ Deo SS, Mahadik SR, Chogle AR, Soneji SL, Lulla $\mathrm{CP}$ : Insulin sensitivity as a risk factor for common carotid intima media thickness (IMT): its relation to atherosclerosis. Clin Exp Hypertens 2007;29:445-455.

6 Avenell A, Broom J, Brown TJ, Poobalan A, Aucott L, Stearns SC, Smith WC, Jung RT, Campbell MK Grant AM: Systematic review of the long-term effects and economic consequences of treatments for obesity and implications for health improvement. Health Technol Assess 2004;8:iii-iv, 1-182.

7 Cannon C P.TIMI Study Group: Obesity-related cardiometabolic complications. Clin Cornerstone 2008;9:11-22.

${ }_{8}$ Noakes M,Keogh JB, Foster PR, Clifton PM: Effect of an energy-restricted, high-protein, lowfat diet relative to a conventional high-carbohydrate, low-fat diet on weight loss, body composition, nutritional status, and markers of cardiovascular health in obese women. Am J Clin Nutr 2005;81:1298-1306.

$\checkmark$ Golay A, Buclin S, Ybarra J, Toti F, Pichard C, Picco N, De Tonnac N, Allaz AF: New interdisciplinary cognitive-behavioural-nutritional approach to obesity treatment: a 5-year follow-up study. Eat Weight Disord 2004;9:29-34.
10 Buclin-Thiébaud S, Pataky Z, Bruchez V.Golay A: New psycho-pedagogic approach to obesity treatment: a 5-year follow-up. Patient Educ Couns 2010;79:333-337.

11 Makoundou V, Bobbioni-Harsch E, Gachoud JP, Pataky Z, Golay A: A 2-year multifactor approach of weight loss maintenance. Eat Weight Disord. 2010;15:e9-e14

12 Mazzone AM, Urbani MP, Picano E, Paterni M, Borgatti E, De Fabritiis A, Landini L: In vivo ultrasound parametric imaging of carotid atherosclerosis plaque by videodensitometric technique. Angiology 1995;46:663-672.

13 Anderson JW, Konz EC: Obesity and disease management: effects of weight loss on comorbid conditions. Obes Res 2001;9(suppl 4):326S-334S.

14 Goldstein DJ: Beneficial health effects or modest weight loss. Int J Obes 1992;16:397-415.

15 Tuomilehto J, Lindström J, Eriksson JG, Valle TT, Hämäläinen H, Ilanne-Parikka P, KeinänenKiukaanniemi S, Laakso M, Louheranta A, Rastas M, Salminen V, Uusitupa M; Finnish Diabetes Prevention Study Group: Prevention of type 2 diabetes mellitus by changes in lifestyle among subjects with impaired glucose tolerance. N Engl Med 2001;344:1343-1350.

16 Brehm BJ, d'Alessio DA: Weight loss and metabolic benefits with diets of varying fat and carbohydrate content: separating the wheat from the chaff. Nat Clin Pract Endocrinol Metable 2008;4: 140-146.

17 Win RR, Hill JO: Successful weight loss maintenance. Annu Rev Nutr 2001;21:323-341.

18 Wing RR, Tate DF, Gorin AA, Raynor HA, Fava JL: A self-regulation program for maintenance of weight loss. N Engl J Med 2006;355:1563-1571.

19 Lahti-Koski M, Männistö S, Pietinen P, Vartiainen E: Prevalence of weight cycling and its relation to health indicators in Finland. Obes Res 2005;13:333-341.
20 Assali AR, Ganor A, BeigelY, Shafer Z, Hershcovici $T$ : Insulin resistance in obesity: body-weight or energy balance. J Endocrinol 2001;171:293-298.

21 Schenk S, Harber MP, Shrivastava CR, Burant CF ,Horowitz JF: Improved insulin sensitivity after weight loss and exercise training is mediated by a reduction in plasma fatty acid mobilization, not enhanced oxidative capacity. J Physiol 2009;587: 4949-4961.

22 Klein S, Luu K, Fontana L, Young VL, Coggan AR, Kilo C, Patterson BW, Mohammed BS: Absence of an effect of liposuction on insulin action and risk factors for coronary heart disease. $\mathrm{N}$ Engl Med 2004;350:2549-2557.

23 Oyama LM, do Nascimento CM, Carnier J, de Piano A, Tock L, de Lima Sanches P, Gomes FA, Tufik S, de Mello MT, Dâmaso AR: The role of anorexigenic and orexigenic neuropeptides and peripheral signals on quartiles of weight loss in obese adolescents. Neuropeptides 2010;44:467-474.

24 Hidvégi T, Szatmári F, Hetyési K, Bíró L, Jermendy G: Intima-media thickness of the carotid arteries in with hyperinsulinemia(insulin resistance). Diabetes Nutr Metab 2003;16:139-144.

25 Bokemark L, Wikstrand J, Attvall S, Hulthe J, Wedel H, Fagerberg BL: Insulin resistance and intima-media thickness in the carotid and femoral arteries of clinically healthy 58 -year old men: the atherosclerosis and insulin resistance study (AIR). J Intern Med 2001;249:59-67.

26 Wohlin M, Sundström J, Arnlöv J, Andrén B, Zethelius B, Lind L: Impaired insulin sensitivity is an independent predictor of common carotid intima-media thickness in a population sample of elderly men. Atherosclerosis 2003;170:181-185.

27 Kawamoto R, Tomita H, Ohtsuka N, Inoue A, Kamitani A: Metabolic syndrome, diabetes and subclinical atherosclerosis as assessed by carotid intima-media thickness. J Atheroscler Thromb 2007;14:78-85. 